This item was submitted to Loughborough's Research Repository by the author.

Items in Figshare are protected by copyright, with all rights reserved, unless otherwise indicated.

\title{
The role of field-assisted techniques in solid/liquid separation
}

PLEASE CITE THE PUBLISHED VERSION

PUBLISHER

(C) Elsevier

VERSION

AM (Accepted Manuscript)

LICENCE

CC BY-NC-ND 4.0

REPOSITORY RECORD

Tarleton, E.S.. 2009. “The Role of Field-assisted Techniques in Solid/liquid Separation”. figshare. https://hdl.handle.net/2134/5280. 
This item was submitted to Loughborough's Institutional Repository (https://dspace.lboro.ac.uk/) by the author and is made available under the following Creative Commons Licence conditions.

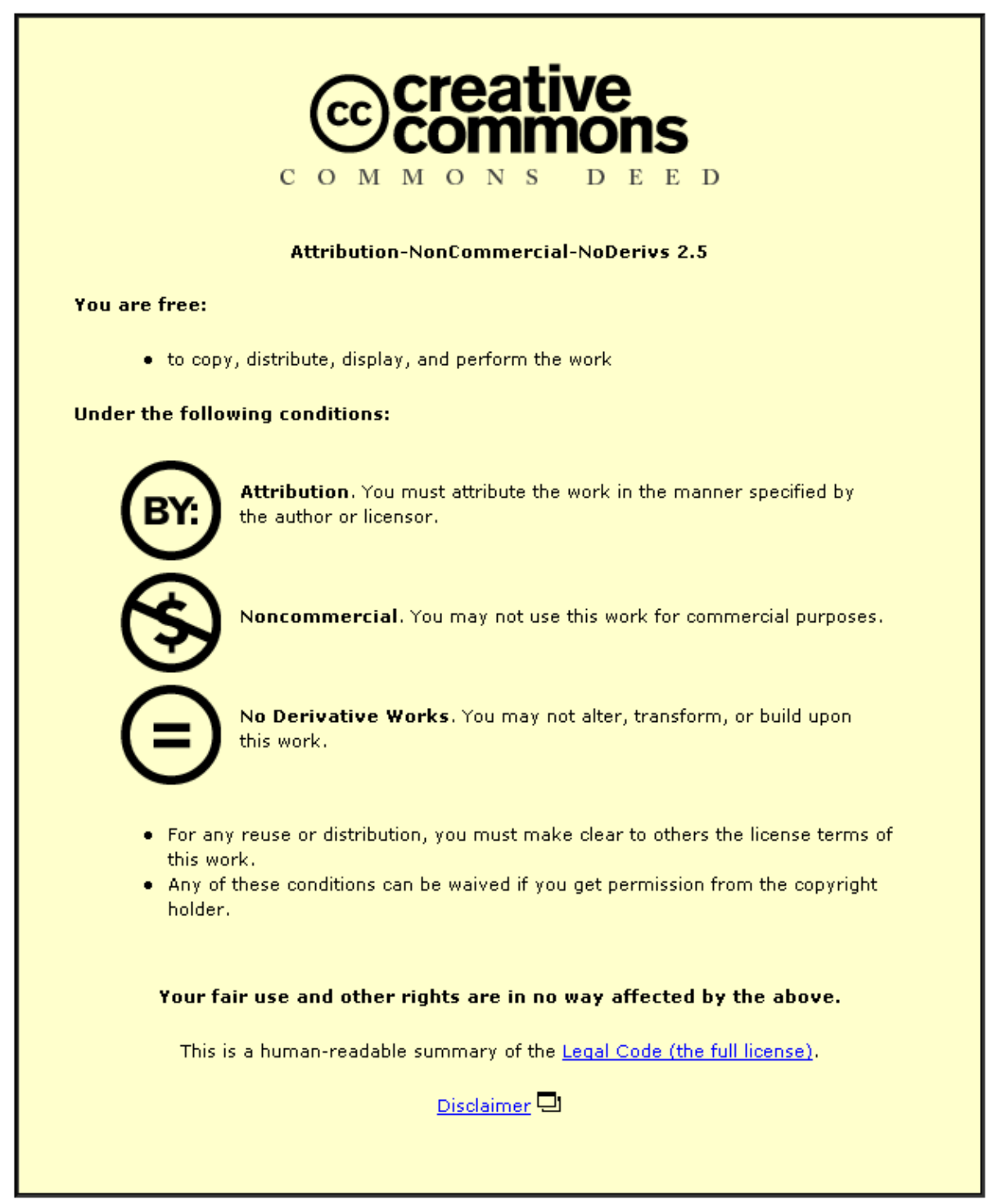

For the full text of this licence, please go to: http://creativecommons.org/licenses/by-nc-nd/2.5/ 


\title{
THE ROLE OF FIELD ASSISTED TECHNIQUES IN SOLID/LIQUID SEPARATION
}

\author{
E.S. Tarleton (e.s.tarleton@lboro.ac.uk) \\ Separation Processes Centre, University of Exeter, Exeter, UK.
}

\begin{abstract}
The separation of finer particle suspensions into constituent solid and liquid components is difficult to achieve. Field assisted separations which utilise the forces generated by applied electric, acoustic or magnetic fields are becoming an increasingly viable alternative to the more conventional, frequently ill-suited, techniques used presently. An overview is given of the development of the more pertinent assisted separation techniques and illustrates their performance with experimental data obtained by the author. The data show how improved separation rates can be achieved with imposed force fields, often at lower overall energy inputs per unit of product. Current and possible future applications of assisted separations are discussed both in terms of equipment performance and economic considerations.
\end{abstract}

\section{INTRODUCTION}

The separation of solid/liquid systems has become an important topic in both industry and academia. Driven by ever stricter legislation from governments and international bodies, industry has to manufacture its products with a minimum of damage to the environment whilst attempting to maintain their own competitiveness in the market place. This need for improved efficiency (at a realistic cost) has fuelled research not only into existing separation methods but also provided the impetus to develop new technologies. These technologies, frequently invented and nurtured in the laboratories of academic institutions, address the growing problem of processing feed streams, and perhaps more importantly waste streams, containing finer particulates. Against such a background 'field assisted separations' have emerged at the forefront of separation science technology $y^{1-10}$.

Conventional separations such as pressure or vacuum filtration, centrifugation and expression rely to a large extent on mechanical force(s) to remove unwanted liquor from suspension. However, the processing of finer feeds using these techniques is frequently uneconomic, difficult to achieve and time consuming due to the dominant influences of surface effects and particle-particle interactions. Assisted separations which combine electric, sonic, ultrasonic and/or magnetic field forces with more conventional apparatus can enhance the removal of many particle species by utilising intrinsic properties like surface electrical charge and magnetism. Here, the reliance on mechanical force (and energy) is reduced and the separation achieved by supplementing the process with energy supplied from a well directed external force field. The fields improve separation performance to provide greater recovery, often at lower energy costs per unit of product. Advances in technology have allowed the better understanding of assisted separation to the extent that commercial units capable of operation at small, medium and large scales exist or are now being introduced onto the market ${ }^{1,2,11,12}$.

This paper outlines how assisted separation techniques have progressed to their current state and attempts to describe possible future uses. Experimental data obtained from a range of laboratory scale equipment by the author are presented in conjunction with theoretical considerations to illustrate the basic principles and potential advantages of using imposed force fields. The parameters affecting separation efficiency under different conditions are identified and discussed.

\section{SEPARATIONS INCORPORATING ELECTRIC FIELDS}


The effects of electric fields in solid/liquid separation were first observed in the early part of the nineteenth century. Reuss ${ }^{13}$ studied how electric fields could influence the filtration of aqueous clay suspensions: upon applying a DC field across a suspension supported by a porous diaphragm water migrated through the diaphragm (electroosmosis) whilst clay particles moved in the opposite direction, towards the electrode suspended above the filtering surface (electrophoresis). From this early discovery a number of commercial processes and patents evolved ${ }^{14-19}$. Most of the viable processes up to the 1930's employed DC electric fields to promote the dewatering of fine particle beds. Perhaps the best known were the electroosmotic filter presses installed at plants in Germany, Austria and Czechoslovakia which were capable of producing about 15 tons day ${ }^{-1}$ of dry clay at power consumptions equivalent to $20 \mathrm{kWh} \mathrm{ton}^{-1}$. Between 1930 and the early 1980's further applications of electrofiltration were few with most projects being abandoned due to comparable costs with conventional separation techniques ${ }^{19-22}$. In recent years, however, a combination of academic research, improved technology and the emergence of crossflow filtration at the industrial level as a means of suspension dewatering has focussed interest on using electrokinetic effects to reduce membrane fouling ${ }^{3,8,23-27}$.

The crossflow processes such as microfiltration (MF) and ultrafiltration (UF) were conceived to dewater fine particulate suspensions (typical size ranges $0.05-20 \mu \mathrm{m}$ and 0.001-0.1 $\mu \mathrm{m}$ respectively) by preventing the formation of deposits or cakes at the filtering surface through shear generated forces. Whilst crossflow velocities of up to $6-8 \mathrm{~m} \mathrm{~s}^{-1}$ are used industrially the shear rates generated are frequently insufficient to prevent significant membrane fouling by particulates. The low filtrate flux levels which ensue are undesirable and prevent the more widespread application of the technologies. Although the mechanisms of fouling are currently the subject of on-going research programmes ${ }^{28,29}$, it is clear that the contribution of particulate fouling to flux decline can be reduced by introducing an electric field gradient $(E)$ to impart an electrophoretic velocity $(v)$ to the charged particles in the feed stream in a direction away from the filter surface such that

$$
v=\frac{2 \varepsilon \zeta E}{3 \mu}
$$

where $\varepsilon$ is the permittivity of the fluid medium, $\zeta$ the particle zeta potential and $\mu$ the fluid medium dynamic viscosity. Figure 1 illustrates a typical electrofilter which comprises a planar semipermeable membrane sandwiched between two electrodes enclosed within a filter chamber. During filtration the feed suspension is transported via a flow circuit through the annular space in the electrofilter where a suitably polarised DC constant voltage potential gradient in the range 0$100 \mathrm{~V} \mathrm{~cm}^{-1}$ is applied between the two electrodes. Figure 2 shows some typical data: an imposed field induced electrophoretic velocities to particles in the feed stream causing less foulants to accumulate at the separating surface and so facilitating both a more open cake structure and a substantially increased filtrate flux. Moreover, such results were obtained with crossflow velocities of $0.1 \mathrm{~m} \mathrm{~s}^{-1}$. The use of crossflows over an order of magnitude less than those commonly found in industrial filters offers potential advantages in terms of reduced pumping costs, less heat input, the improved processing of shear sensitive streams such as bio-feeds and reduced overall power requirements for the filtration (see later). Tests have shown ${ }^{30}$ that the effects illustrated in Figure 2 can be repeated with a range of sub- $5 \mu \mathrm{m}$ aqueous suspensions provided the zeta potential (a measure of electrical surface charge) of the solid phase is greater than $|20| \mathrm{mV}$. The extent of the increase in filtration rates by electric fields is primarily reliant on these two factors and the applied field gradient with the electrical power consumed dependent on the conductivity of the feed stream and the electrode separation.

While electric fields are potentially well suited as an aid to membrane related separations, their use is not necessarily confined to this area of solid/liquid separation. In recent years researchers have attempted to couple electric fields with batch and continuous settling ${ }^{31-33}$, sludge dewatering ${ }^{22,34-36}$, deadend vacuum filtration ${ }^{33,37,38}$ and a number of other separation devices ${ }^{39,40}$. Although varying degrees of success have been claimed for each application none have as yet yielded an 
economically viable industrial process. However, some success has been achieved in the area of dielectrophoretic separations which utilise non-uniform AC or DC electric fields to separate particulates in the range $0.01-50 \mu \mathrm{m}$ from dilute non-aqueous media. The process relies on polarising particles in the feed stream to re-distribute their surface and/or internal electric charge. This in turn causes particle migration toward an electrode. For a perfect dielectric sphere the polarisation yields a translational force $\left(F_{e}\right)$ of

$F_{e}=2 \pi r^{3} \frac{\varepsilon_{f}\left(\varepsilon_{p}-\varepsilon_{f}\right)}{\varepsilon_{p}+2 \varepsilon_{f}} \nabla\left(E^{2}\right)$

where $r$ is the radius of the sphere, $\nabla\left(E^{2}\right)$ is the slope of the undisturbed electric field gradient (squared) and $\varepsilon_{f}$ and $\varepsilon_{p}$ are the absolute permittivities of the fluid medium and particles respectively ${ }^{9}$. In most cases $\varepsilon_{p}>\varepsilon_{f}$ and particles move toward the region of higher field intensity under the action of electric field gradients in the range $500-10^{4} \mathrm{~V} \mathrm{~cm}^{-1}$. To be competitive dielectrophoretic techniques must be capable of separating particulates from the finer size ranges, however, equation (2) shows that the force exerted on particles rapidly decreases with particle radius. Whilst attempts have been made at a laboratory scale to utilise dielectrophoresis in a crossflow mode with wire and plate or wire and cylinder electrodes ${ }^{41,42}$ the devices have foundered at larger scales (using 'real' suspensions) due to difficulties of conduction, suspension decomposition and electric field generation. In recent years some of these difficulties have been overcome with the advent of High Gradient Dielectrophoretic Separators (HGDS) ${ }^{43}$. Here, the section between the electrodes is filled by a matrix of finely divided dielectric material such as ceramic wool or glass beads having a bulk porosity of approximately $75 \%$ (see Figure 3 ). When an electric field is applied the high field gradients produced at the matrix surfaces impart large dielectrophoretic forces to the particulates in the feed, so enhancing particle capture and producing clarified liquor downstream of the separator. Such developments have allowed dielectrophoretic separations to be performed at micron levels in the petroleum, biotechnology and vegetable oil industries ${ }^{9,43}$.

\section{SEPARATIONS INCORPORATING ULTRASONIC FIELDS}

Until recently, reports on the uses of ultrasonic fields with sound frequencies $>16 \mathrm{kHz}$ in solid/liquid separation were restricted to a few, largely qualitative, papers that illustrated some basic applications and physico-chemical effects of sound waves ${ }^{44-50}$. Whilst it seems that ultrasound could be utilised to sometimes enhance settling ${ }^{46}$ (by causing agglomeration of particles) and increase liquid flow rates through filters ${ }^{49}$ its use with particulate suspensions went almost unreported until the mid-to-late 1980's when data was published concerning batch cake dewatering ${ }^{5,51-53}$. Here, experiments were performed at a laboratory scale with combined electric and ultrasonic fields to enhance the dewatering rates of coal, sewage and mineral sludges such as phosphate slimes. With the technically improved ultrasonic equipment now available there has been a developing interest in ultrasonics to the extent that a small scale continuous filter, claimed to be capable of efficiently processing pigment and fine ceramic dispersions, has recently become commercially available ${ }^{11}$.

The author has been involved in projects using ultrasonics since the mid 1980's as a natural extension of previous work with electric fields to reduce fouling in crossflow microfiltration ${ }^{3,27,30,54,55}$ Initial work proved inconclusive ${ }^{56}$ but further development with refined techniques has produced significant results ${ }^{7,57}$. The filtration apparatus used, shown schematically in Figure 4, comprised a continuous flow circuit in which a pressure driven filter cell containing a microfiltration membrane was mounted. The cell allowed operation in either deadend or crossflow modes (with velocities up to $0.2 \mathrm{~m} \mathrm{~s}^{-1}$ ) and included the addition of two $23 \mathrm{kHz}$ ultrasonic horns. The horns, produced nominal power intensities up to $3 \mathrm{~W} \mathrm{~cm}^{-2}$, and were mounted on the upstream side of the membrane such that the sound waves transmitted through the slurry impinged onto the surface of 
any deposit formed at the septum. Figure 5 shows some data obtained for the filtration of an aqueous china clay suspension both with and without ultrasonic assistance. The increase in flux seen when the sound waves were applied is indicative of a change in both the structure and the amount of the deposit fouling the membrane surfaces.

The passage of a sound wave through a suspension is described by the wave equation with the sound intensity at any distance $x$ from the source $\left(I_{x}\right)$ given by

$I_{x}=I_{0} \exp (-\alpha x)$

and related to the ultrasound frequency $(f)$ through a constant of proportionality $(k)$ by

$$
\log \left(I_{x}\right)=\log \left(I_{0}\right)-k f^{2} x
$$

where $\alpha$ is the intensity absorption coefficient and $I_{0}$ the ultrasound source strength. In accordance with equations ( 3 ) \& (4) and others ${ }^{58,59}$ it was found experimentally that the degree of flux enhancement with ultrasonic assistance increased at smaller particle sizes and raised field intensities and decreased at higher suspension viscosities, concentrations and ultrasound frequencies ${ }^{7,57}$.

When ultrasonic sound waves are applied to a suspension the waves propagate through the mixture in the form of mechanical vibratory energy. At the solid/liquid phase boundaries high inertial forces are generated that may be of sufficient magnitude to cause effects such as particulate dispersion, viscosity reduction, changes in the surface properties of the particles in suspension and perhaps most pertinently cavitation. The latter is manifested as the rapid formation, oscillation, growth and subsequent violent destruction of gaseous microbubbles and initiates from nucleation sites. In a filtration system these sites occur on vessel walls, suspended particulates, existing air bubbles in the fluid medium, particles forming fouling layers and membrane pores. It has been estimated ${ }^{7}$ that a typical microbubble with diameter $\sim 30 \mu \mathrm{m}$ originating at a pore throat in the septum could rise against a filtrate flux of up to $2 \mathrm{~m}^{3} \mathrm{~m}^{-2} \mathrm{~h}^{-1}$ to contact a fouling layer. Many such bubbles are thought to dislodge the fouling layers sufficiently during their growth and destruction to allow even low crossflows to re-entrain constituent particulates and produce flux improvements similar to those shown in Figure 5.

\section{SEPARATIONS INCORPORATING MAGNETIC FIELDS}

The basic principles of magnetic separation have been known and applied commercially now since the latter part of the $19^{\text {th }}$ century ${ }^{60}$. Until the 1970's, however, only Low Gradient Magnetic Separators (LGMS) were available for the separation of relatively large particulate $(>75 \mu \mathrm{m})$, strongly magnetic materials such as tramp metal from suspension and for the purification and enrichment of magnetic ores such as haematite. These devices incorporate relatively low flux density magnets $(<2 \mathrm{~T})$ in continuous drum or belt type configurations to process feeds containing up to 30-40 weight $\%$ solids. Whilst such equipment is used widely in industry today of more interest here is the emergence and subsequent application of High Gradient Magnetic Separation $(\mathrm{HGMS})^{61,62}$.

Magnetic separation usually involves passing a suspension through a region where a non-uniform magnetic field acts. If the particles in suspension exhibit a positive susceptibility to the magnetic field they are attracted toward the region of highest field strength. Table 1 shows that materials can be classified into four categories of descending 'magnetic response'.

Whilst materials of the first two classifications listed in Table 1 can be processed successfully with LGMS the low magnetic response of paramagnetic and diamagnetic materials prevents its use and 
HGMS must be substituted. Figure 6 shows a schematic representation of typical HGMS apparatus. The equipment comprises a chamber filled with a matrix of fine steel filaments (cf. HGDS). During operation the suspension passes through the matrix and separation occurs provided the solid phase is sufficiently susceptible to the action of the applied magnetic field. A typical HGMS would utilise electromagnets or superconducting magnets capable of operation at fields up to $8 \mathrm{~T}$ and be able to process dilute aqueous suspensions carrying particulates in the range $0.1-100 \mu \mathrm{m}$. As the feed stream passes through the matrix the field gradients generated at the surfaces of the filaments enhance the entrapment of particles and allow the clarified liquor to pass through. The force $\left(F_{m}\right)$ experienced by a spherical particle passing through a magnetic field $B_{0}$ is given by

$F_{M}=\frac{X\left(\frac{4}{3} \pi r^{3}\right)\left(B_{0} \nabla B_{0}\right)}{\mu_{0}}$

where $r$ is the particle radius, $x$ the magnetic susceptibility of the particle, $\mu_{0}$ the permeability of free space and $\nabla B_{0}$ the magnetic field gradient ${ }^{1}$. When sufficient particles have been deposited a 'filter cake' begins to form and the solids handling capacity of the matrix is reached. Here, the matrix can be regenerated by either reducing or switching off the magnetic field and backflushing, or preferably withdrawing the matrix to wash the particles free. Thus, in order to operate on a continuous basis high gradient magnetic separators are frequently used in some sort of tandem arrangement such that separation can continue whilst a matrix is cleaned.

Although ongoing research is continuing into the potential applications of LGMS and HGMS in solid/liquid separation ${ }^{63-66}$ (and solid/gas separation) a variety of previous projects have already produced successes in the area of mineral processing ${ }^{1,67}$. For instance the polishing of china clay to remove the ferrous content and improve brightness has been successfully performed at a large scale for several years now. The ability to efficiently process paramagnetic suspensions, and even weakly paramagnetic and diamagnetic particles by seeding (with for instance magnetite), to produce clean liquid products (contamination levels of $1 \mathrm{ppm}-1 \mathrm{ppb}$ are not uncommon) with a minimum of equipment maintenance are likely to see magnetic separation processes used more extensively in the future.

\section{SEPARATIONS INCORPORATING COMBINED FIELDS}

The assisted field techniques discussed to date in this paper all utilise a single force field. Of equal interest, however, has been the more recent development of combined field technologies which use two force fields to promote synergistic effects ${ }^{5,7,52,56,57}$. Figure 7 shows data from a typical experiment involving the simultaneous application of electric and ultrasonic fields during the crossflow filtration of an aqueous china clay suspension. The individual fields were both able to improve flux performance to some extent, but the combined fields applied simultaneously produced a filtrate flux significantly better than the simple additive effects of the individual fields. Although such synergistic effects can be repeated for a range of experimental conditions and suspension types in field assisted crossflow microfiltration ${ }^{7,57}$ (and sludge dewatering ${ }^{5,52}$ ) the underlying mechanisms of the process are currently difficult to identify. Despite the suggestion of a number of hypothetical models indicating preferential interactions between the imposed force fields and the process suspension their applicability is yet to be proven and the analysis of combined field filtration remains largely experimentally based.

\section{DISCUSSION}


The enhancement of solid/liquid separation with imposed force fields has been attempted many times during the past century. Consequently the technologies have been 're-discovered' many times over only to fade into relative oblivion again after a few years in the limelight. However, the last twenty years has seen a sustained interest and growth in assisted separation techniques. Their evolution has been driven by the range of economic and environmental considerations facing today's industries under the realisation that conventional separation techniques are often ill-suited to many process requirements.

The use of imposed force fields has always provided the separations technologist with many challenges. The apparent complexities of the mechanisms of operation have often resulted in theoretical aspects being considered at a relatively simplistic level in an attempt to explain experimental results. Since the advent of computers and computer driven test equipment such as laser diffraction particle size analysers, engineers and scientists have had the facilities readily available to enhance the understanding of the interactions between suspensions and imposed field forces at a more fundamental level. Whilst undoubted progress has been made to bring revolutionary processes such as HGDS and in particular HGMS to a commercially viable status there still remain apparently un-resolved problems with other assisted separation techniques. Their slower development is perhaps indicative of the difficulties involved in persuading industry to accept that such techniques could prove useful in the commercial environment. A criticism sometimes levelled at techniques such as electrofiltration is that the power requirements for the separation are either not quoted or too high to allow economic operation. The experimental data in this paper have shown that both individual and combined electric and ultrasonic fields can enhance flux performance in crossflow microfiltration. Table 2 demonstrates that such effects can be produced at significantly lower overall energy inputs.

The data in Table 2 show the contributions to the power consumed by the filter system for the pump used to provide the crossflow, the constant voltage $\left(50 \mathrm{~V} \mathrm{~cm}^{-1}\right)$ D.C. electric field and the 23 $\mathrm{kHz}\left(1.7 \mathrm{~W} \mathrm{~cm}^{-2} \mathrm{~cm}^{-1}\right)$ ultrasonic field. The power input figures are quoted per unit membrane area whilst the energy consumed is expressed per unit volume of filtrate. Experiments performed with no imposed force fields (for comparison purposes) employed a crossflow of $2.3 \mathrm{~m} \mathrm{~s}^{-1}$ whereas all the assisted filtrations used the much lower crossflow of $0.1 \mathrm{~m} \mathrm{~s}^{-1}$. Although actual power inputs with imposed fields were in all cases higher than the corresponding tests with no fields the data highlight that the energy required to produce a unit volume of filtrate was decreased significantly for both anatase and china clay suspensions over a range of solids concentrations when combined electric and ultrasonic fields were used. Moreover, the time taken to extract a unit volume of filtrate from each suspension was reduced with the combined fields by $x 4, x 18, x 4$ and $x 10$ respectively. Although the data in Table 2 is encouraging it should be viewed in the light that to date little attempt has been made to minimise the power consumed by either the electric or ultrasonic fields. There would seem considerable scope to reduce power inputs significantly further and make imposed field separations even more attractive.

Whilst the future for assisted separations is continually improving the information obtained to date only provides, in some cases, the basic elements from which further work can develop. Projects investigated recently such as magnetic labelling ${ }^{10,68}$, pulsed field electrofiltration ${ }^{3,69}$ and electroosmosis $^{70}$, electrofiltration with rotating filter elements ${ }^{25,71}$ and the manufacture of ceramic membranes specifically for use in electrofiltration ${ }^{72}$ have all grown from an upsurge in research interest. Such work indicates the current level of interest in assisted separations and can only result in these processes becoming more viable in the future.

\section{CONCLUSIONS}

Since their conception, field assisted separation techniques have been considered by many to be 'technologies awaiting applications'. Previous attempts to utilise the techniques at anything above a laboratory scale have often foundered on either economic grounds or practical difficulties, but 
there is now an increased understanding and awareness for their uses. Some techniques, such as LGMS and HGMS, have emerged as commercial processes whilst others like electro- and electroacoustic filtration show great promise. The ability to process finer particle suspensions efficiently is likely to become an increasingly important requirement for many solid/liquid separations in the future. Field assisted and combined field separations would appear to provide the necessary technology by which these objectives can be achieved.

\section{ACKNOWLEDGEMENT}

The data presented in this paper were obtained from a variety of projects funded by the Science and Engineering Research Council Specially Promoted Programme in Particulate Technology. The grants supporting the work are gratefully acknowledged as is the additional support from the company members of the Separation Processes Centre at Exeter University.

\section{REFERENCES}

1. J.H.P. Watson, in Solid-Liquid Separation, $3^{\text {rd }}$ Edn., L. Svarovsky (Ed.), pp.661-684, Butterworths, London, 1990.

2. H.S. Muralidhara, Proc. $V^{\text {th }}$ World Filtration Congress, pp.74-79 (Vol. 1), Sociètè Française de Filtration, Nice, France, June 1990.

3. R.J. Wakeman and E.S. Tarleton, Chem. Eng. Sci., 42(4), 829, 1987.

4. J.D. Henry, L.F. Lawler and C.H.A. Kuo, AlChEJ, 23(6), 851, 1977.

5. H.S. Muralidhara, D. Ensminger and A. Putnam, Drying Tech., 3(4), 529, 1985.

6. R. Ben Aim, Proc. $V^{\text {th }}$ World Filtration Congress, pp.507-511 (Vol. 1), Sociètè Française de Filtration, Nice, France, June 1990.

7. R.J. Wakeman and E.S. Tarleton, Trans. IChemE, 69(A), 386, 1991.

8. W.R. Bowen, Paper presented at Filtration Society R\&D meeting, Exeter, Devon UK, $20^{\text {th }}$ April, 1988.

9. I.J. Lin and L. Benguigui, in Progress in Filtration and Separation, Vol. 3, R.J. Wakeman (Ed.), pp.149-204, Elsevier, Amsterdam, 1983.

10. C.P. Bowden, G. Leaver, J. Melling, M.G. Norton and P.N. Whittington, in Separations for Biotechnology, M.S. Verrall and M.J. Hudson (Ed.), pp.49-61, Ellis Horwood, Chichester, 1987.

11. K. Miyazaki, Y. Takahasi and K. Shiomi, Filtration and Separation, 27(1), 28, 1990.

12. Prof. Grebeniuk, Paper presented at $12^{\text {th }}$ International Symposium on Desalination and Water Re-use, Valetta, Malta, April 1991.

13. H.J. Creighton, Principles and Applications of Electrochemistry, Vol. 1, $4^{\text {th }}$ Edn., pp.143-165, Chapman and Hall, London, 1943.

14. U.S. Patent $89,470$.

15. U.S. Patent $720,186$. 
16. U.K. Patent $21,441$.

17. H. Beechold, in Colloid Chemistry, Vol. 2, J. Alexander (Ed.), The Chemical Catalog Company, 1926.

18. E. Manegold, Trans. Faraday. Soc., 33, 1088, 1937.

19. C. Rampacek, in Solid-Liquid Separation, J.B. Poole and D. Doyle (Eds.), pp.100-108, HMSO, London, 1966.

20. A.E. Murphy, Trans. Inst. Rubber Ind., 18, 137, 1942.

21. M.P. Freeman, Paper presented at Orlando '82 AIChE meeting, Orlando, Florida, 28 Feb - 3 Mar, 1979.

22. N.C. Lockhart, in Advances in Solid-Liquid Separation, H.S. Muralidhara (Ed.), pp.241-274, Batelle, Ohio, 1986.

23. H. Yukawa, K. Shimura, A. Suda and A. Maniwa, J. Chem. Eng. Japan, 16(4), 305, 1983.

24. J.M. Radovich, B.M. Dotson and C. Ho, J. Coatings Tech., 52(663), 47, 1980.

25. Turkson A.K., Proc. Filtech Conf., pp.294-301, Filtration Society, Utrecht, Holland, 1987.

26. C. Visvanathan and R. Ben Aim, Sep. Sci. Tech., 24(5 and 6), 383, 1989.

27. E.S. Tarleton and R.J. Wakeman, Drying Tech., 6(3), 547, 1988.

28. R.J. Wakeman and E.S. Tarleton, Desalination, 83, 35, 1991.

29. M.R. Hoogland, C.J.D. Fell, A.G. Fane and D.A.R. Jones, Proc. $V^{\text {th }}$ World Filtration Congress, pp.604-610 (Vol. 1), Sociètè Française de Filtration, Nice, France, June 1990.

30. E.S. Tarleton, PhD Thesis, University of Exeter, 1986.

31. M. Shirato, T. Aragaki, A. Manabe and N. Takeuchi, AIChEJ, 25(5), 855, 1979.

32. K. Matsumoto, O. Kutowy and C.E. Capes, Pow. Tech., 31, 197, 1982.

33. H. Yukawa, K. Kobayashi, H. Yoshida and M. Iwata, in Progress in Filtration and Separation, Vol. 1, R.J. Wakeman (Ed.), pp.83-112, Elsevier, Amsterdam, 1979.

34. H. Yukawa, H. Yoshida, K. Kobayashi and M. Hakoda, J. Chem. Eng. Japan, 9(5), 402, 1976.

35. N.C. Lockhart, Int. J. Min. Proc., 10, 131, 1983.

36. W.R. Bowen and A.D. Turner, in Solid-Liquid Separation, J. Gregory (Ed.), pp.11-28, Ellis Horwood, Chichester, 1984.

37. S.P. Moulik, F.C. Cooper and M.J. Bier, J. Colloid Interface Sci., 24, 427, 1967.

38. R.J. Wakeman, Filtration and Separation, 19(4), 316, 1982.

39. H. Yukawa, K. Kobayashi and M. Hakoda, J. Chem. Eng. Japan, 13(5), 390, 1980. 
40. M. Aho, T. Tuori and P. Pirkonen, Proc. Filtech Conf., pp.238-245, Filtration Society, Karlsruhe, Germany, 1989.

41. C.H. Lee, D. Gidaspow and D.T. Wasan, Ind. Eng. Chem. Fundam., 19(2), 166, 1980.

42. B.M. Verdegan, Sep. Sci. Tech., 21(6 and 7), 603, 1986.

43. H.A. Pohl, Dielectrophoresis, Cambridge University Press, Cambridge, 1978.

44. H.K. Johnston, CEP Symposium Series No. 109, 67, 39, 1971.

45. A. Weissler, Ultrasonics Symposium Series No. 1, 47, 22, 1950.

46. H.R. Anada, Y.T. Shah and G.E. Klinzing, Can. J. Chem. Eng., 52, 715, 1974.

47. S.K. Nicol, M.D. Engel and K.C. Teh, Int. J. Min. Proc., 17, 143, 1986.

48. K. Sollner, Ultrasonics Symposium Series No. 1, 47, 715, 1950.

49. H.V. Fairbanks and W.I. Chen, Ultrasonics, July, 196, 1969.

50. A. Semmelink, Proc. Ultrasonics Symposium, pp.7-10, IPC Science and Technology, Guildford, 1973.

51. H.S. Muralidhara, U.S. Patent 4,561,953.

52. H.S. Muralidhara, N. Senapati and R.B. Beard, in Advances in Solid-Liquid Separation, H.S. Muralidhara (Ed.), pp.335-374, Batelle, Ohio, 1986.

53. H.S. Muralidhara, H. Hampel and H. Kröebning, Drying Tech., 6(3), 535, 1988.

54. R.J. Wakeman and E.S. Tarleton, Proc. $4^{\text {th }}$ World Filtration Congress, pp.11.1-11.10, KVIV/Filtration Society, Ostend, Belgium, April 1986.

55. R.J. Wakeman and E.S. Tarleton, Filtration and Separation, 23(3), 174, 1986.

56. E.S. Tarleton, Filtration and Separation, 25(6), 402, 1988.

57. E.S. Tarleton and R.J. Wakeman, Filtration and Separation, 27(3), 192, 1990.

58. R.J. Urick, J. Acous. Soc. Am., 20(3), 283, 1948.

59. N.E. Sherman, PhD Thesis, University of Cambridge, 1989.

60. R.H. Perry and D. Green, Perry's Chemical Engineers' Handbook, $6^{\text {th }}$ Edn., pp.21.33-21.41, McGraw Hill, 1984.

61. U.Ts. Andres, in Progress in Filtration and Separation, Vol. 2, R.J. Wakeman (Ed.), pp.125170, Elsevier, Amsterdam, 1981.

62. R.R. Birss and M.R. Parker, in Progress in Filtration and Separation, Vol. 2, R.J. Wakeman (Ed.), pp.171-303, Elsevier, Amsterdam, 1981. 
63. L.F.M. van Velson and R. Boersma, Proc. $V^{\text {th }}$ World Filtration Congress, pp.331-336 (Vol. 2), Sociètè Française de Filtration, Nice, France, June 1990.

64. L. Dolle, Proc. Filtech Conf., pp.44-52, Filtration Society, Utrecht, Holland, 1987.

65. L.E. Macaskie and A.C.R. Dean, J. Gen. Microbiol., 130, 53, 1984.

66. J.W. Anderson, T.J. Veasey and I.S. Wells, IChemE Symposium Series 113, 17, 1989.

67. B.A. Wills, Mineral Processing Technology, $4^{\text {th }}$ Edn., pp.596-634, Pergamon, Oxford, 1988.

68. J.H.P. Watson and D.C. Ellwood, Proc. Filtech Conf., pp.551-556, Filtration Society, Utrecht, Holland, 1987.

69. R. Ben Aim, private communication.

70. N.C. Lockhart and G.H. Hart, Drying Tech., 6(3), 415, 1988.

71. J.A. Mikhlin, M.E. Weber and A.K. Turkson, J. Separ. Proc. Technol., 3(1), 16, 1982.

72. C. Guizard, F. Legault, N. Idrissi, A. Larbot, L. Cot and C. Gavach, J. Mem. Sci., 41, 127, 1989. 
FIGURES AND TABLES

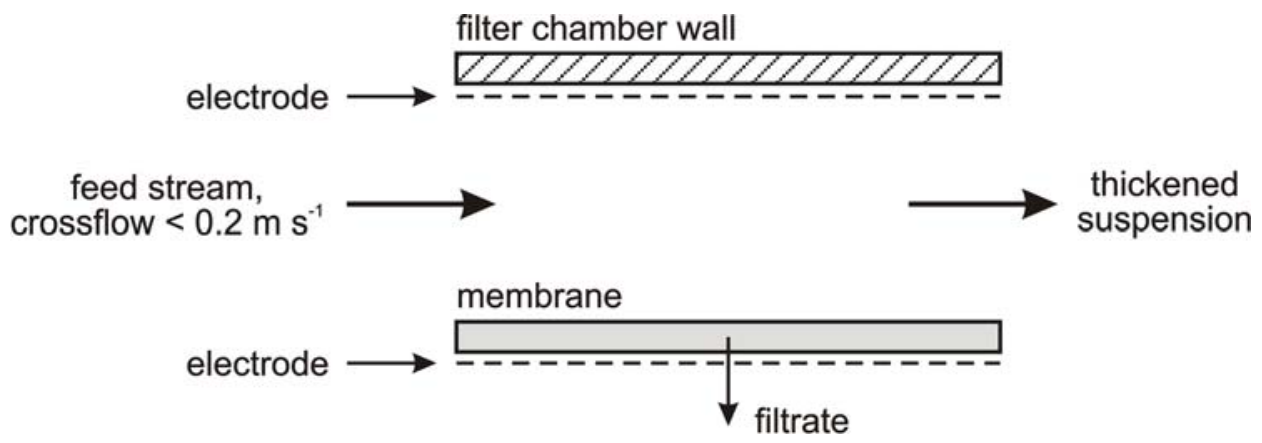

Figure 1: Schematic diagram of a crossflow electrofilter.

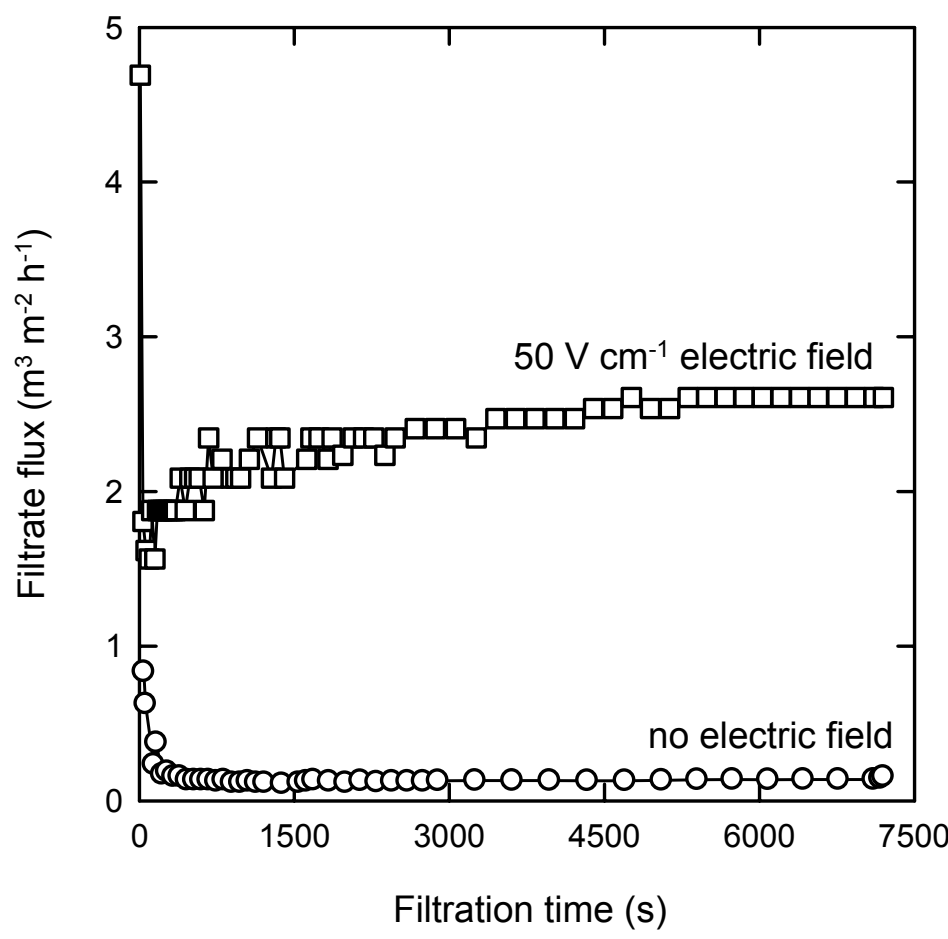

Figure 2: Typical effect of an imposed electric field in crossflow microfiltration. No ultrasonic field; Solids - anatase; Crossflow velocity $-0.1 \mathrm{~m} \mathrm{~s}^{-1}$; Filtration pressure - $140 \mathrm{kPa}$; Suspension conc. $0.6 \%$ by volume. 


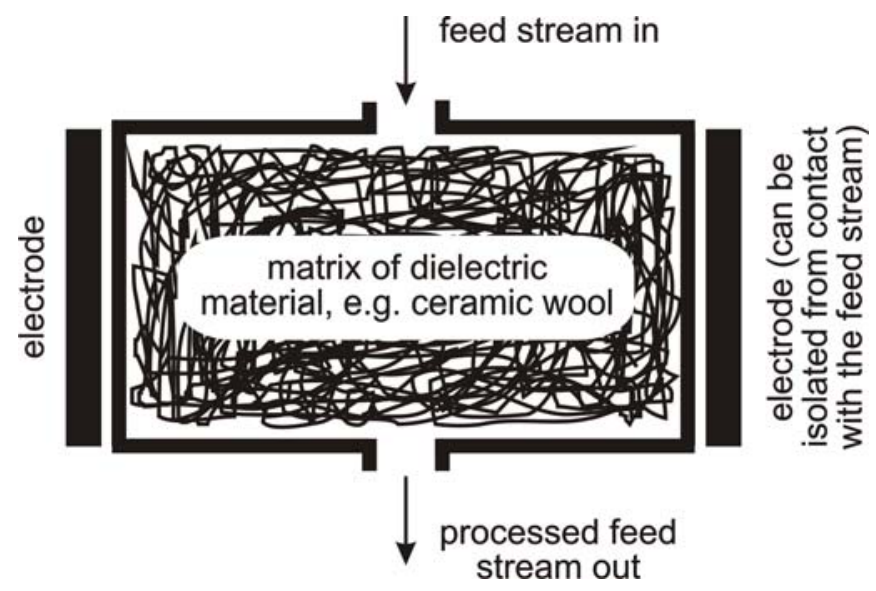

Figure 3: Schematic diagram of a high gradient dielectrophoretic separator.

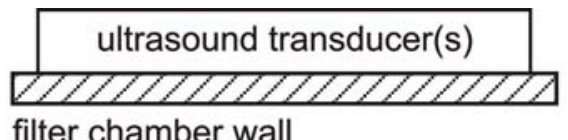

filter chamber wall

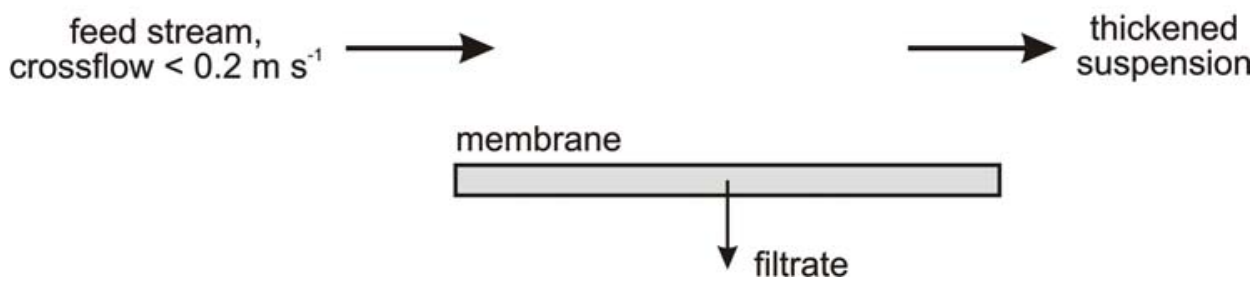

Figure 4: Schematic diagram of a crossflow electroacoustic filter. 


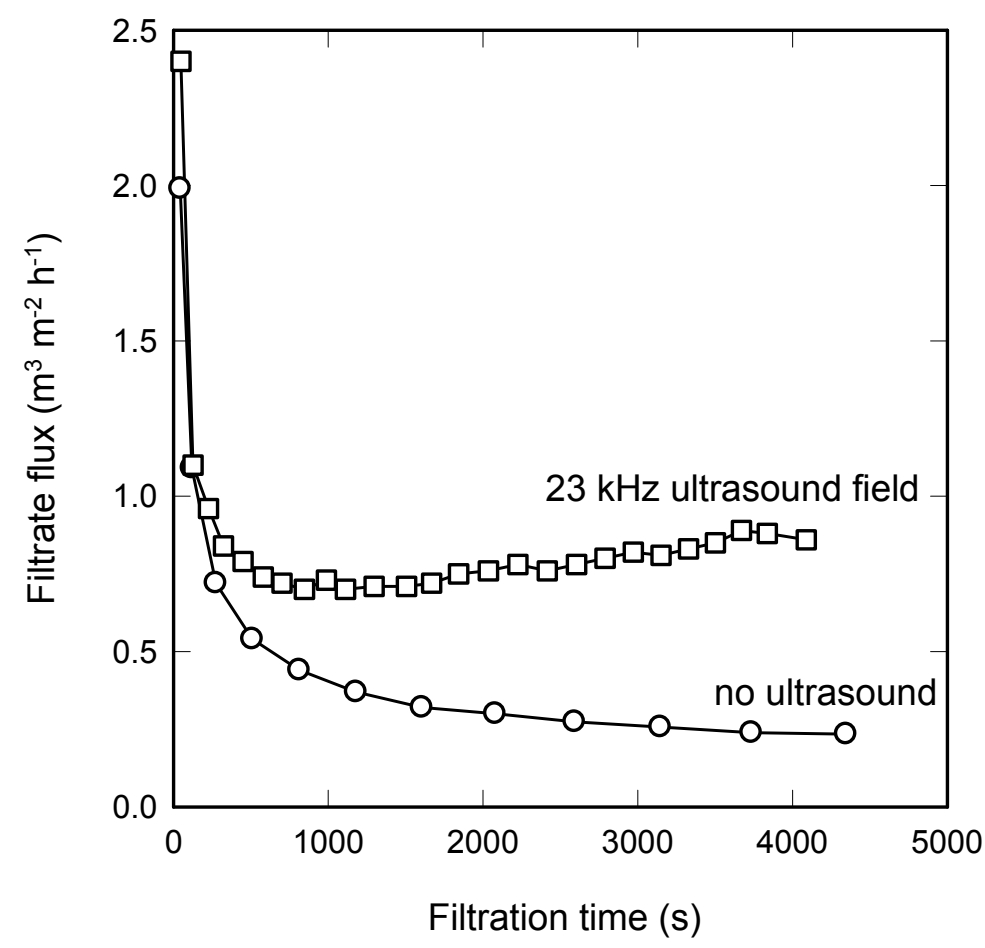

Figure 5: Typical effect of an imposed ultrasonic field in crossflow microfiltration. Ultrasonic density gradient $-0.8 \mathrm{~W} \mathrm{~cm}^{-2} \mathrm{~cm}^{-1}$; No electric field; Solids - china clay; Crossflow velocity $-0.1 \mathrm{~m} \mathrm{~s}^{-1}$; Filtration pressure $-140 \mathrm{kPa}$; Suspension conc. $-0.1 \%$ by volume.

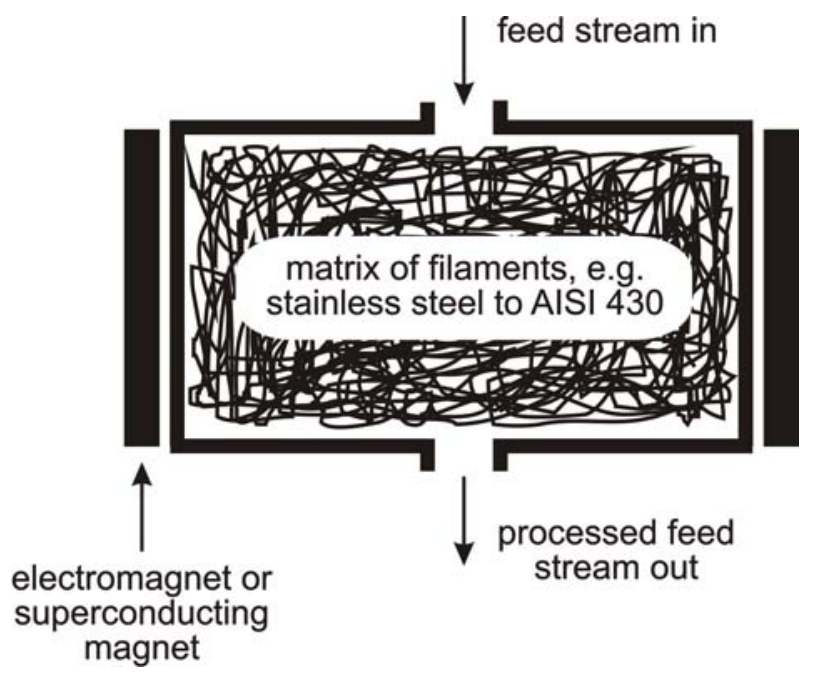

Figure 6: Schematic diagram of a high gradient magnetic separator. 


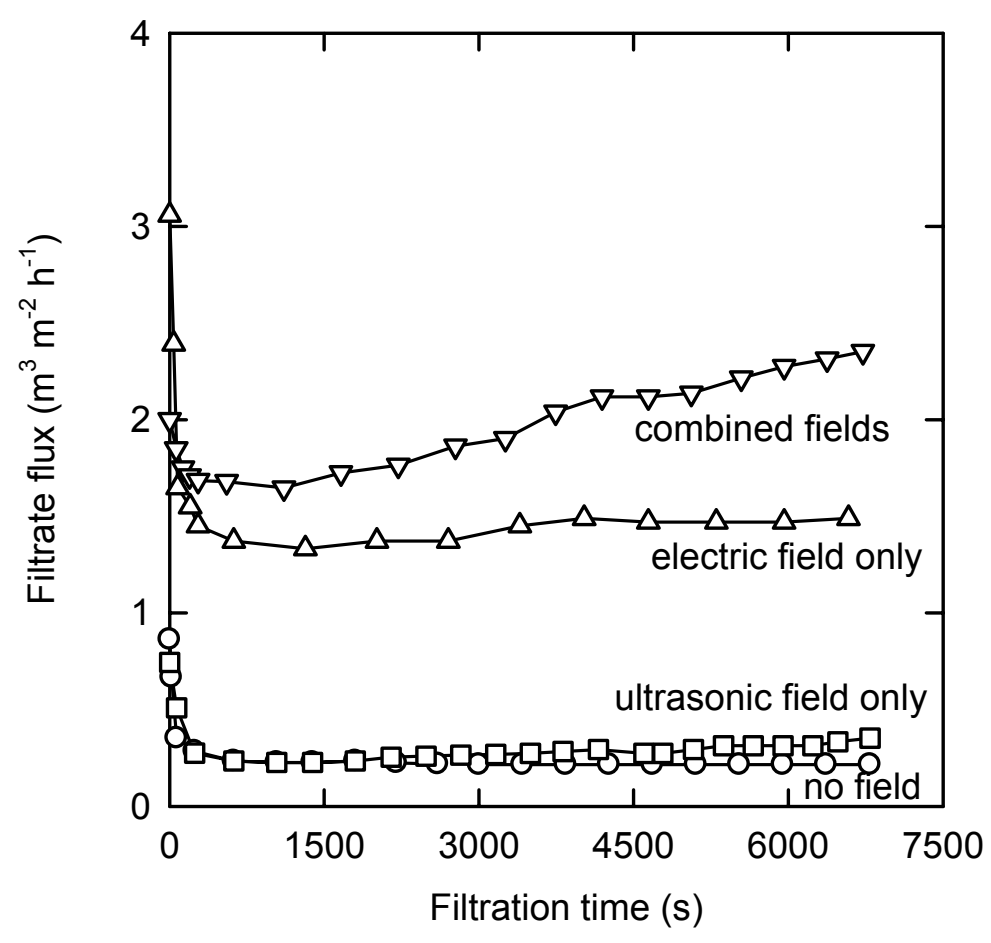

Figure 7: Typical effects of combined force fields in crossflow microfiltration. Field gradients $-50 \mathrm{~V}$ $\mathrm{cm}^{-1}, 1.7 \mathrm{~W} \mathrm{~cm} \mathrm{~cm}^{-1}$; Solids - china clay; Crossflow velocity $-0.1 \mathrm{~m} \mathrm{~s}^{-1}$; Filtration pressure -140 $\mathrm{kPa}$; Suspension conc. $-1.4 \%$ by volume. 


\begin{tabular}{|l|c|l|}
\hline Classification & Magnetic response & Example materials \\
\hline Ferromagnetic & high & iron, steel \\
Ferrimagnetic & $\downarrow$ & haematite, magnetite and limonite \\
Paramagnetic & $\downarrow$ & china clay, talc and fluorspar \\
Diamagnetic & low & proteins \\
\hline
\end{tabular}

Table 1: Magnetic response and classifications of materials.

\begin{tabular}{|c|c|c|}
\hline Process conditions & $\begin{array}{l}\text { Power inputs to system, pump }+ \\
\text { electric + ultrasonic field }\left(\mathrm{kW} \mathrm{m}^{-2}\right)\end{array}$ & $\begin{array}{c}\text { Energy input per unit } \\
\text { volume of filtrate }\left(\mathrm{kWh} \mathrm{m}^{-3}\right)\end{array}$ \\
\hline $\begin{array}{l}0.6 \% \mathrm{v} / \mathrm{v} \text { anatase suspension } \\
\text { no fields } \\
\text { electric field only } \\
\text { ultrasonic field only } \\
\text { combined fields }\end{array}$ & $\begin{array}{l}19.6+0+0=19.6 \\
0.02+27.37+0=27.39 \\
0.02+0+24.90=24.92 \\
0.02+27.96+24.90=52.88\end{array}$ & $\begin{array}{l}32.7 \\
17.6 \\
85.9 \\
23.1\end{array}$ \\
\hline $\begin{array}{l}2.8 \% \mathrm{v} / \mathrm{v} \text { anatase suspension } \\
\text { no fields } \\
\text { electric field only } \\
\text { ultrasonic field only } \\
\text { combined fields }\end{array}$ & $\begin{array}{l}19.6+0+0=19.6 \\
0.02+93.9+0=93.92 \\
0.02+0+24.90=24.92 \\
0.02+124.7+24.90=149.62\end{array}$ & $\begin{array}{c}89.1 \\
132.3 \\
113.3 \\
33.9\end{array}$ \\
\hline $\begin{array}{l}0.6 \% \mathrm{v} / \mathrm{v} \text { china clay suspension } \\
\text { no fields } \\
\text { electric field only } \\
\text { ultrasonic field only } \\
\text { combined fields }\end{array}$ & $\begin{array}{l}19.6+0+0=19.6 \\
0.02+6.65+0=6.67 \\
0.02+0+24.90=24.92 \\
0.02+8.60+24.90=33.52\end{array}$ & $\begin{array}{l}26.1 \\
9.26 \\
46.6 \\
11.1\end{array}$ \\
\hline $\begin{array}{l}1.4 \% \text { v/v china clay suspension } \\
\text { no fields } \\
\text { electric field only } \\
\text { ultrasonic field only } \\
\text { combined fields }\end{array}$ & $\begin{array}{l}19.6+0+0=19.6 \\
0.02+9.1+0=9.12 \\
0.02+0+24.90=24.92 \\
0.02+13.0+24.90=37.92\end{array}$ & $\begin{array}{l}39.3 \\
6.08 \\
62.3 \\
16.5\end{array}$ \\
\hline
\end{tabular}

Table 2: Power consumptions during field assisted and conventional MF. 